\title{
RESEARCH OF AIR POLLUTION BY FINE SUSPENDED PARTICULAR MATER IN THE CITY OF ZAPOROZHYE
}

Sevalnev A.I., Volkova Yu.v.

\section{ДОСЛІДЖЕННЯ ЗАБРУДНЕННЯ ПОВТТРЯНОГО БАСЕЙНУ ДРІБНОДИСПЕРСНИМИ ЗВАЖЕНИМИ ТВЕРДИМИ ЧАСТИНКАМИ У М. ЗАПОРІЖЖЯ}

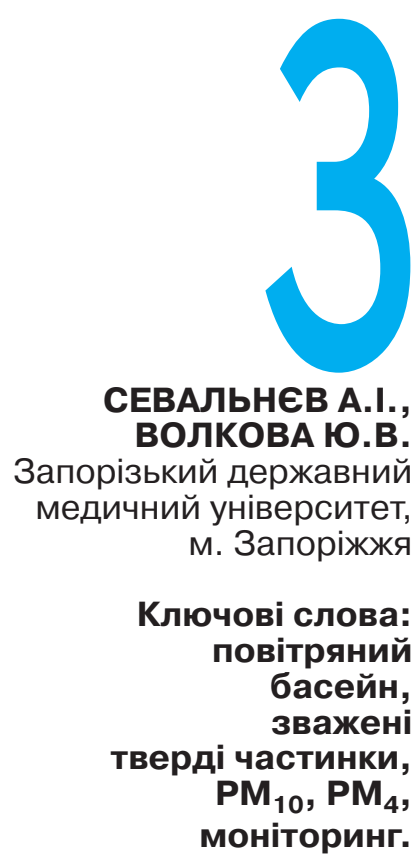

моніторинг. абруднення повітря $є$ пріоритетним фактором екологічного ризику для здоров'я й однією з провідних причин захворюваності та смертності в усьому світі. За останніми даними експертів Всесвітньої організації охорони здоров'я (ВООЗ, 2018), 9 з 10 людей дихають повітрям з високою концентрацією забруднюючих речовин [1]. Найбільшу небезпеку для життя та здоров'я становлять зважені тверді частинки дрібнодисперсних фракцій $\mathrm{PM}_{10}$ та $\mathrm{PM}_{2,5}$. Це пояснюється їхнім широким розповсюдженням, хімічним складом, розміром, можливістю вторинного утворення в атмосфері з інших газоподібних прекурсорів тощо. 3 впливом цих забруднювачів повітря пов'язаний підвищений ризик розвитку серцево-судинних, респіраторних захворювань, виникнення онкопатології, а також скорочення тривалості життя у середньому на 8,6 місяців та мільйони випадків передчасної смертності у світі щороку [2, 3].

у більшості країн світу існують законодавчі документи з нормування вмісту зважених твердих частинок $\mathrm{PM}_{10}$ та $\mathrm{PM}_{2,5}$, здійснюється постійний моніторинг вмісту цих речовин в атмосферному повітрі.

В Україні донині нормативи вмісту $\mathrm{PM}_{10}$ та $\mathrm{PM}_{2,5}$ в атмосферному повітрі не були розроблені, відповідно й динамічне спостереження за їх вмістом у повітрі на державному рівні не здійснюється. Даний факт унеможливлює коректну оцінку стану забруднення атмосферного повітря й, відповідно, його впливу на здоров'я населення.

Зрозуміло, що у таких умовах проведення гігієнічних досліджень 3 визначення стану забруднення повітря дрібнодисперсними фракціями зважених твердих частинок $\epsilon$ необхідною складовою для прогнозування екологічної ситуації та наукового обґрунту-
ИССЛЕДОВАНИЕ ЗАГРЯЗНЕНИЯ ВОЗДУШНОГО БАССЕЙНА МЕЛКОДИСПЕРСНЫМИ ВЗВЕШЕННЫМИ ТВЕРДЫМИ ЧАСТИЦАМИ В Г. ЗАПОРОЖЬЕ

Севальнев А.И., Волкова Ю.В.

Запорожский государственный медицинский университет, г. Запорожье

Цель работы - гигиеническая оценка состояния загрязнения воздушного бассейна мелкодисперсными взвешенными твердыми частицами $\mathrm{PM}_{10}$ и $\mathrm{PM}_{4}$ ) в г. Запорожье.

Материалы и методы. Измерения концентраций мелкодисперсных взвешенных твердых частиц $P M_{10}$ и $\mathrm{PM}_{4}$ проводились с 2012 г. по 2017 г. в атмосферном воздухе г. Запорожье. Для измерений был использован анализатор аэрозолей KANOMAX-3521. Обработка полученных данных проводилась с помощью статистического пакета лицензионной программы «STATISTICA ${ }^{\circledR}$ for Windows 13.0» (StatSoft Inc., № JPZ8041382130FRCN10-J) и «Microsoft Excel». Результаты. Установлено, что концентрации PM 10 в г. Запорожье превышают уровни, рекомендованные в руководящих принципах по ка- честву атмосферного воздуха ВОЗ. Средние концентрации по городу РМ $10-(0,14 \pm 0,002)$ $\mathrm{Mr} / \mathrm{M}^{3}, \mathrm{PM}_{4}-(0,07 \pm 0,001) \mathrm{Mr} / \mathrm{M}^{3}$, в Вознесеновском районе концентрации $P M_{10} B$ 1,2 раза достоверно выше $(p<0,05)$. В опытных районах концентрации $P M_{10}$ в 1,08-1,9 раз достоверно выше ( $p<0,001)$, чем в контрольном. Максимальные концентрации регистрировались в августе (коэффициент сезонности 1,8-1,83). Установлена сильная обратная корреляционная связь между относительной влажностью воздуха и концентрацией $P M_{10}(r=-0,85)$ и $P M_{4}$ $(r=-0,83)$ и статистически значимая разница между концентрациями данных веществ в вечерние и утренние часы суток $(p<0,001)$. Результаты исследования указывают на необходимость организации постоянного мониторинга содержания мелкодисперсных взвешенных твердых частиц и разработку гигиенического нормативного документа для РМ.

Ключевые слова: воздушный бассейн, взвешенные твердые частицы, PM $_{10}, P_{4}$, мониторинг.

( Севальнєв А.І., Волкова Ю.В. СТАТТЯ, 2019. 
RESEARCH OF AIR POLLUTION BY FINE SUSPENDED PARTICULAR MATER IN THE CITY OF ZAPORIZHZHYA

Sevalnev A.l., Volkova Yu.V.

Zaporozhye State Medical University

Objective: The aim of the work is a hygienic estimation of the air pollution condition by fine suspended particular mater $\left(P M_{10}\right.$ and $\left.P M_{4}\right)$ in the city of Zaporizhzhya. Materials and methods. The measurements of fine suspended particular mater $P M_{10}$ and $P M_{4}$ have been carried out since 2012 to 2017 years in the atmospheric air of Zaporizhzhya. It was used the KANOMAX-3521 aerosol analyzer for measurements. The data processing was performed with the statistical package of the licensed program «STATISTICA $®$ for Windows 13.0» (StatSoft Inc., No. JPZ8041382130FRCN10-J) and the «Microsoft Excel» program.

Results. It has been established that $P M_{10}$ concentrations in the air of Zaporizhzhya exceed the recommended levels by the WHO guidelines for air quality. The average concentrations of $P M_{10}$ in the city $-(0.14 \pm 0.002) \mathrm{mg} / \mathrm{m}^{3}, P M_{4}-(0.07 \pm 0.001)$ $\mathrm{mg} / \mathrm{m}^{3}$, the concentration of $P M_{10}$ is 1.2 times higher $(p<0.05)$ in the Voznesenovsky district. In the experimental areas, the concentration of $P M_{10}$ is 1.08-1.9 times significantly higher $(p<0.001)$ than in the control area. Maximal index of concentration was recorded in August (seasonality coefficient 1.8-1.83). It was established a strong inverse correlation between the relative humidity of the air and the concentration of $P M_{10}(r=-0.85)$ and $P M_{4}$ $(r=-0.83)$ and the statistically significant difference between the concentrations of these substances in the evening and in the morning hours of the day $(p<0.001)$

The results of the research indicate the necessity to organize the continuous monitoring of the fine suspended particular mater content in the air and the creation of a hygienic regulatory document for the PM.

Keywords: air pool, suspended particulate mater, $P M_{10}, \mathrm{PM}_{4}$, monitoring. вання напрямків природоохоронної діяльності, спрямованих на попередження ризику для здоров'я

у м. Запоріжжя незважаючи на спад потужностей виробництва стан забруднення пазон вимірювання концентрації пилу визначався у межах

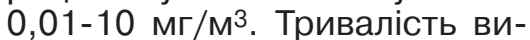
мірювань і період осереднення при визначенні разових концентрацій становили 20 хвилин, реєстрація одиничних значень - щосекундна. Висота вимірювань - 1,5 м. Заміри супроводжувалися вимірами температури, відносної вологості, напряму і швидкості руху повітря, атмосферного тиску вимірювачем параметрів мік-

Середні концентрації $\mathrm{PM}_{10}$ та $\mathrm{PM}_{4}$ в атмосферному повітрі у 2012 році

\begin{tabular}{|c|c|c|c|c|c|c|}
\hline \multirow{3}{*}{ Район міста } & \multicolumn{6}{|c|}{ Концентрація, мкг/м³ } \\
\hline & \multicolumn{3}{|c|}{$\mathrm{PM}_{10}$} & \multicolumn{3}{|c|}{$\mathrm{PM}_{4}$} \\
\hline & $\mathrm{M} \pm \mathrm{m}$ & $\max$ & $\min$ & $\mathrm{M} \pm \mathrm{m}$ & $\max$ & $\min$ \\
\hline Дніпровський & $0,07 \pm 0,015$ & 0,1 & 0,05 & $0,03 \pm 0,013$ & 0,06 & 0,02 \\
\hline Вознесенівський & $0,2 \pm 0,02$ & 0,33 & 0,07 & $0,11 \pm 0,009$ & 0,17 & 0,03 \\
\hline Заводський & $0,12 \pm 0,02$ & 0,21 & 0,06 & $0,07 \pm 0,014$ & 0,12 & 0,02 \\
\hline Комунарський & $0,04 \pm 0,004$ & 0,05 & 0,03 & $0,01 \pm 0,003$ & 0,02 & 0,01 \\
\hline Олександрівський & $0,11 \pm 0,01$ & 0,18 & 0,06 & $0,06 \pm 0,006$ & 0,1 & 0,01 \\
\hline Хортицький & $0,04 \pm 0,005$ & 0,08 & 0,03 & $0,02 \pm 0,003$ & 0,01 & 0,01 \\
\hline Шевченківський & $0,13 \pm 0,01$ & 0,3 & 0,05 & $0,07 \pm 0,007$ & 0,17 & 0,02 \\
\hline
\end{tabular}

повітряного басейну залишається недопустимим. А зважені тверді частинки $€$ основними забруднювачами атмосферного повітря міста $[4,5]$.

Метою даної роботи було визначення та аналіз отриманих концентрацій $\mathrm{PM}_{10}$ та $\mathrm{PM}_{4}$ в атмосферному повітрі районів м. Запоріжжя.

Матеріали та методи. Концентрації зважених твердих частинок дрібнодисперсних фракцій $\mathrm{PM}_{10}$ та $\mathrm{PM}_{4}$ визначали методом п'єзобалансового зважування осадженої проби пилу за допомогою аналізатора аерозолів KANOMAX, модель 3521. Діа-

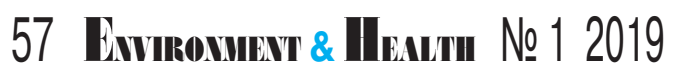

Таблиця 1

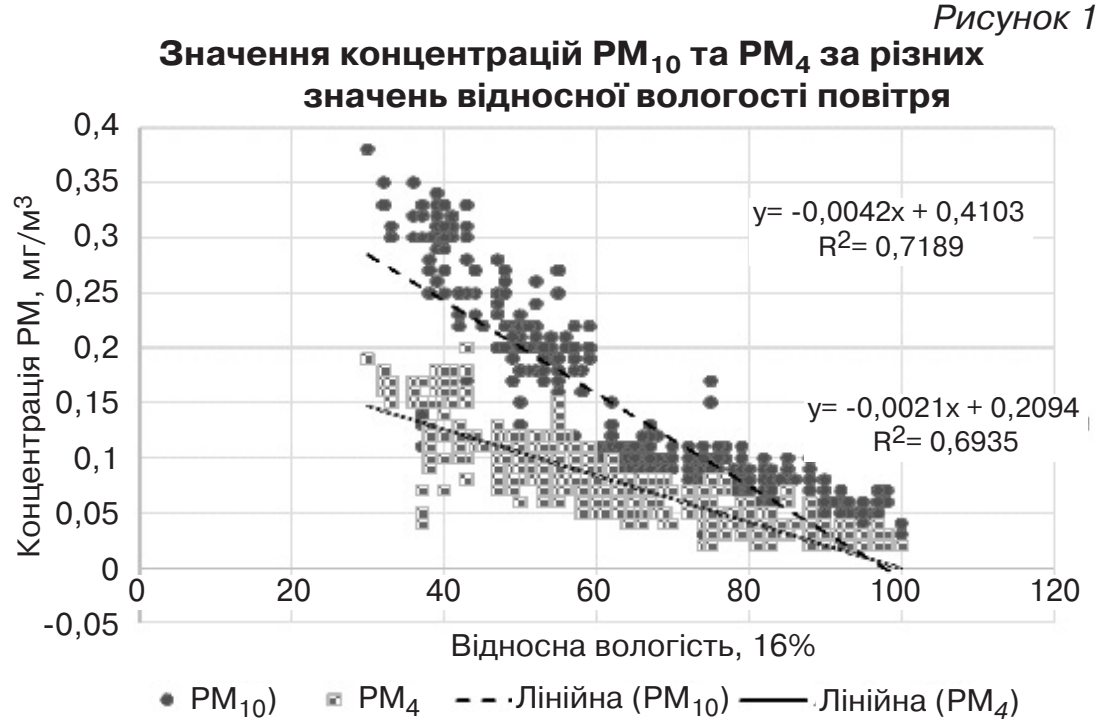


роклімату Метеоскоп «MEC202».

Дослідження здійснювалося у сельбищних зонах м. Запоріжжя з 2012 по 2016 рік. Виміри зважених частинок в атмосферному повітрі проводилися у визначених точках відбору проб повітря двічі на день (8:00-10:00 та 16:0018:00) на відстані $1000-4000$ м від основного промислового майданчика у різні сезони року за відсутності опадів.

Обробка отриманих результатів проводилася за допомо-

Рисунок 2
Концентрації $\mathrm{PM}_{10}$ та $\mathrm{PM}_{4}$ 3 8:00 до 20:00 годин (вул. Сталеварів, 23)

0,12

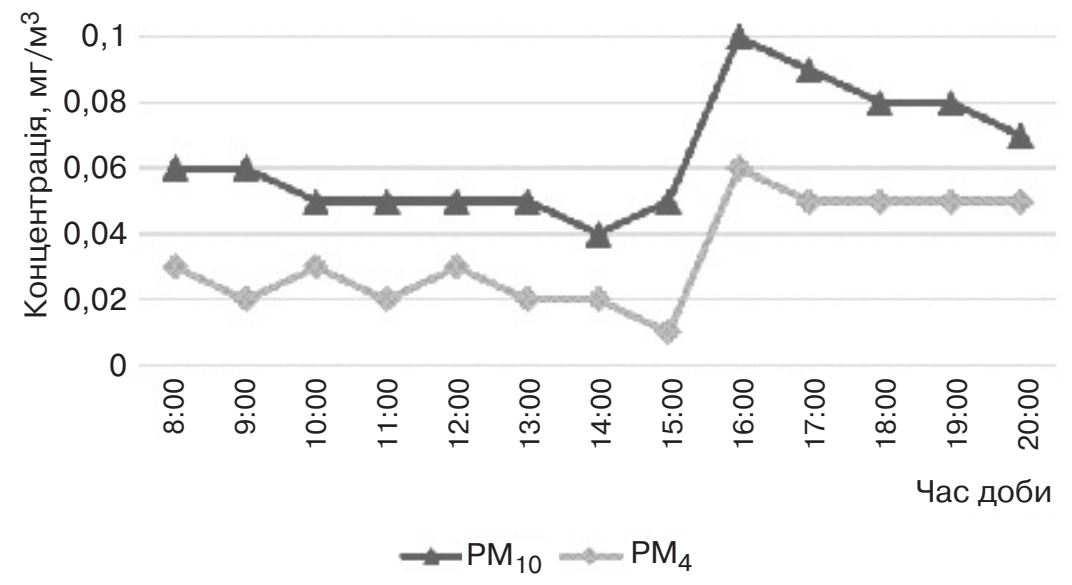

Концентрації $\mathrm{PM}_{10}$ в атмосферному повітрі районів м. Запоріжжя

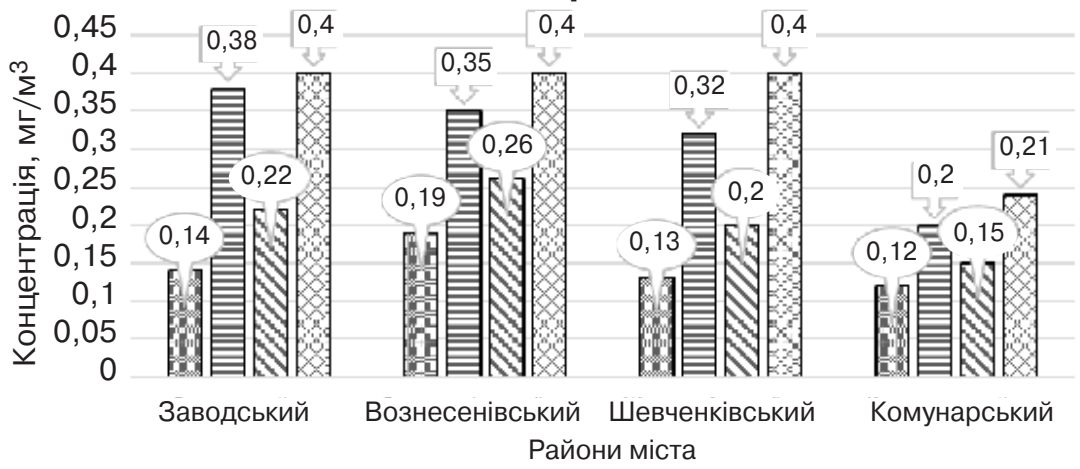

口Середня концентрація $\mathrm{PM}_{10}$ вранці в Максимальна концентрація $\mathrm{PM}_{10}$ вранці 曰 Середня концентрація PM1 10 ввечері 曰 Максимальна концентрація $\mathrm{PM}_{10}$ ввечері

Річна динаміка змін концентрацій PM $_{10}$ в атмосферному повітрі

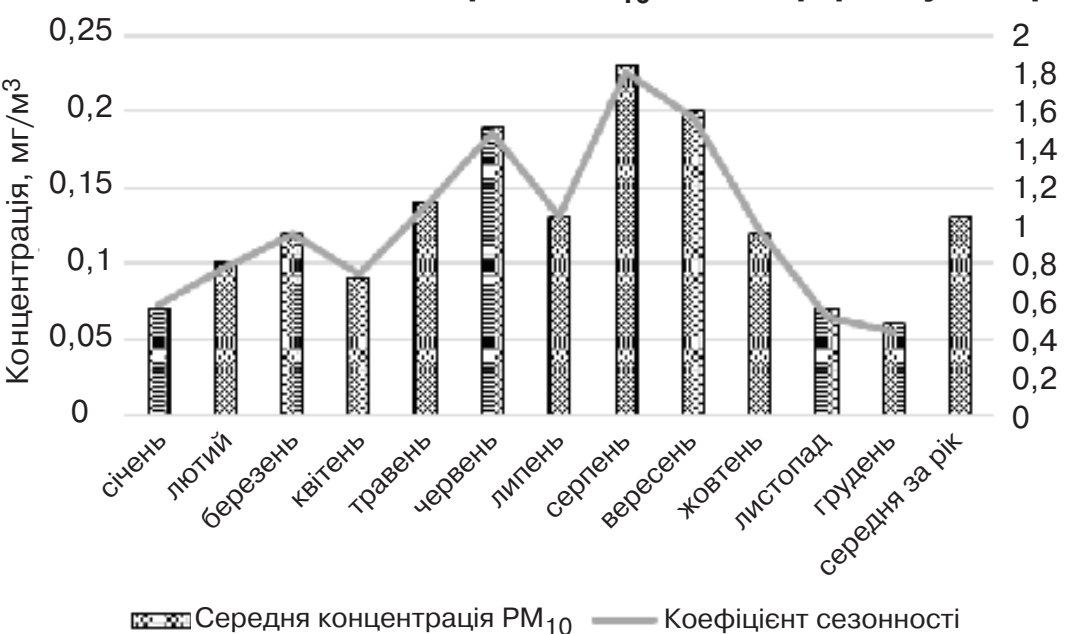

гою статистичного пакета ліцензійної програми «STATISTICA ${ }^{\circledR}$ for Windows 13.0» (StatSoft Inc., № JPZ80413821 30FRCN10-J) i «Microsoft Excel». Статистично значимими вважали відмінності при $p<0,05$.

Результати досліджень. Для оцінки якості атмосферного повітря використовували максимально-разові, середні за місяць та середні за рік концентрації $\mathrm{PM}_{10}$ і $\mathrm{PM}_{4}$. У зв'язку з відсутністю вітчизняних нормативів для дрібнодисперсних зважених твердих частинок отримані результати порівнювалися 3 рівнями, що рекомендовані у керівних принципах 3 якості атмосферного повітря ВООЗ [6].

2012 року нами було виконано перші виміри концентрацій дрібнодисперсних зважених твердих частинок $\mathrm{PM}_{10}$ та $\mathrm{PM}_{4}$ в атмосферному повітрі в усіх районах м. Запоріжжя. Встановлено, що ці забруднювачі $\epsilon$ постійними компонентами повітряного басейну усіх районів міста. Проте концентрації цих речовин у різних районах суттєво відрізняються. Середні концентрації по місту для $\mathrm{PM}_{10}$ становлять $(0,14 \pm 0,009)$ $\mathrm{Mг} / \mathrm{M}^{3}$, а для $\mathrm{PM}_{4}-(0,07 \pm$ $0,006) \mathrm{мг} / \mathrm{M}^{3}$. Найвищі рівні цих аерополлютантів зафіксовано у Вознесенівському, Шевченківському та Заводському районах, а найбільш чистим за цим показником забруднення виявився Комунарський район (табл. 1).

Слід зазначити, що за результатами сумісної роботи, яка проводилася у місті Запоріжжя у 2004 році за підтримки Агентства США з охорони довкілля та ГО «Environmental Defense» (USA), за наукового керівництва фахівців ДУ «Інститут громадського здоров'я імені О.М. Марзєєва НАМН України» щодо використання методології оцінки ризику для пріоритезації природоохоронної діяльності, Вознесенівський та Заводський райони також були віднесені до територій несприятливого ризику за показником забруднення атмосферного повітря пилом $[4,7]$.

3 урахуванням результатів даної роботи та наших попе- 
редніх досліджень [5] було обрано для подальших досліджень 61 вулицю у зазначених трьох найбільш забруднених районах міста (дослідні райони) та 10 вулиць в умовно чистому Комунарському районі (контроль). На цих вулицях нами були визначені точки відбору проб повітря на територіях, прилеглих до дитячих дошкільних закладів, загальноосвітніх шкіл та ліцеїв. Виміри концентрацій $\mathrm{PM}_{10}$ та $\mathrm{PM}_{4}$ проводилися відповідно до напрямку вітру у день дослідження.

у ході дослідження було виявлено сильний зворотній зв'язок між значенням відносної вологості повітря та концентрацією зважених твердих частинок $\mathrm{PM}_{10}$ та $\mathrm{PM}_{4}$, $(\mathrm{r}=-0,85$; $\mathrm{p}<0,05$ та $r=-0,83 ; p<0,05$ відповідно). Дану закономірність візуально продемонстровано на рисунку 1. Встановлено, що при збільшенні відносної вологості на 1 відсоток концентрація $\mathrm{PM}_{10}$ зменшується на 4,2 мкг $/ \mathrm{M}^{3}$, а концентрація

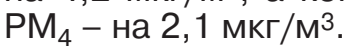

Нами було встановлено, що концентрації забруднювачів, що досліджувалися, протягом доби мають певну динаміку. Так, порівняння середніх значень концентрацій $\mathrm{PM}_{10}$ та $\mathrm{PM}_{4}$ показало, що існує статистично значуща різниця між концентраціями даних речовин у вечірні та у ранкові години доби ( $p<0,001)$.

у середньому їхні концентрації ввечері в 1,5 рази вищі, ніж вранці. Взагалі ця закономірність описується такими рівняннями регресії:

$y=0,062+1,06 x$ (для $\mathrm{PM}_{10}$ ) та $\mathrm{y}=0,03+1,12 x$ (для $\mathrm{PM}_{4}$ ).

Таким чином, знаючи концентрації РМ вранці, можна спрогнозувати їхні концентрації ввечері. Залежність концентрацій зважених твердих частинок дрібнодисперсних фракцій від часу доби на одній з вулиць зображено на рисунку 2.

Порівняння вмісту зважених твердих частинок у різних районах показало (рис. 3), що середні концентрації $\mathrm{PM}_{10}$ вранці у дослідних районах складали від $(0,13 \pm 0,005)$

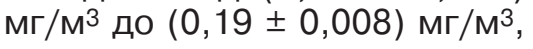

тобто в 1,08-1,58 рази перевищували показники у Комунарському районі, а ввечері кратність перевищення вже становила 1,3-1,73 рази. Максимальні концентрації даних полютантів також у дослідних районах були достовірно вищими порівняно 3 контрольним. Кратність перевищення становила вранці 1,6-1,9 рази, ввечері - 1,7 рази.

Також було встановлено сезонну тенденцію змін концентрації $\mathrm{PM}_{10}$ та $\mathrm{PM}_{4}$. Аналіз показав, що найбільші концентрації досліджуваних речовин спостерігаються у теплий період року, особливо у серпні, а також на початку вересня (рис. 4).

Розраховані нами коефіцієнти сезонності також виявилися найвищими для серпня.

Це пов'язане з метеорологічними особливостями, характерними для м. Запоріжжя: у серпні відбувається збільшення частоти штилів, виникають приземні температурні інверсії, а опади майже відсутні. Це призводить до ускладнення розсіювання забруднювачів та

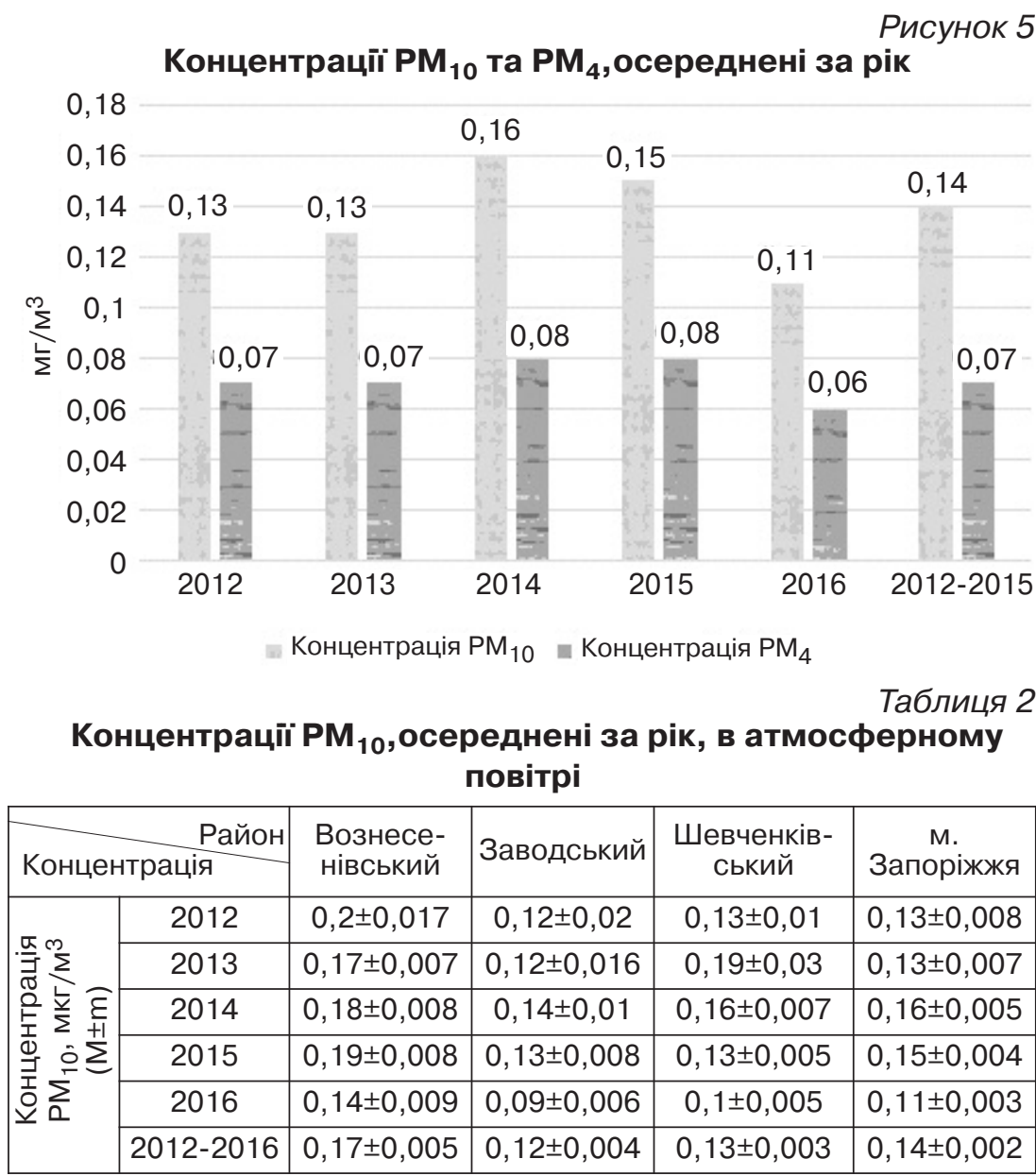

повітрообміну, відповідно до тривалого зависання зважених твердих частинок у повітрі та незначного їх осадження. А високі рівні сонячної радіації сприяють інтенсифікації фотохімічних реакцій, у результаті яких з газоподібних прекурсорів (двоокис сірки, оксиди азоту, аміак і неметанові леткі органічні сполуки) утворюються ще й вторинні зважені тверді частинки.

Розрахунки середніх концентрацій за роками показали, що рівні $\mathrm{PM}_{10}$ загалом по місту за період дослідження

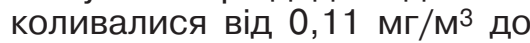
$0,16 \mathrm{Mг} / \mathrm{M}^{3}$ (у середньому $(0,14$ $\left.\pm 0,002) \mathrm{мг} / \mathrm{M}^{3}\right)$, а концентрації

Рисунок 5 
рацій зважених твердих частинок $\mathrm{PM}_{10}$ та $\mathrm{PM}_{4}$ :

口 виявлено достовірний сильний зворотній кореляційний зв'язок між відносною вологістю повітря та концентрацією $\mathrm{PM}_{10}(\mathrm{r}=-0,85)$ і $\mathrm{PM}_{4}$ $(r=-0,83)$.

$\square$ існує статистично значуща різниця між концентраціями даних речовин у вечірні та ранкові години доби ( $p<0,001)$.

口 найбільші концентрації досліджуваних речовин спостерігаються у серпні (індекс сезонності 1,8)

$\square$ у дослідних районах концентрації $\mathrm{PM}_{10}$ та $\mathrm{PM}_{4}$ в 1,081,9 рази достовірно вищі, ніж у контрольному.

3. Результати дослідження вказують на необхідність організації постійного моніторингу вмісту дрібнодисперсних зважених твердих частинок та розробки гігієнічного нормативного документа для РМ.

\section{ЛІТЕРАТУРА}

1. Ambient (outdoor) air quality and health: Fact sheets. WHO, 2018. URL : https://www. who.int/news-room/factsheets/detail/ambient-(outdoor)-air-quality-and-health

2. Health effects of particulate matter. Copenhagen : WHO Regional Office for Europe, 2013. URL:

http://www.euro.who.int/ data /assets/pdf file/0006/189051/ Health-effects-of-particulatematter-final-Eng.pdf

3. Health risks of particulate matter from long-range transboundary air pollution. Copenhagen : WHO Regional Office for Europe, 2006. URL: http://www. euro.who.int/_data /assets/pdf_file/0006/78657/E 88189.pdf

4. Турос О.І. Аналіз ризику для здоров'я населення від забруднення атмосферного повітря промисловими підприємствами м. Запоріжжя Медичні перспективи. 2008. T. XIII. №1. C. 93-97.

5. Севальнєв А.І.,

Волкова Ю.В. Цільове планування заходів щодо зниження ризиків для здоров'я від впливу зважених твердих частинок. Вісник проблем біології $і$ медицини. 2017. Вип. 4.

С. 87-91.

6 . Air quality guidelines -

global update 2005 .
Copenhagen : WHO Regional Office for Europe, 2006. URL: http://www. euro.

who.int/data/assets/pdf file/ 0005/78638/E90038.pdf?ua=1

7. Турос O.І., Петросян А.А., Мазко Л.В. Використання методології ризику при оцінці впливу дрібнодисперсного пилу на стан здоров'я населення. Перший Всеукраїнський з'їзд екологів : зб. тез доп. Вінниця : УНІВЕРСУМ, 2006. C. 244-245.

\section{REFERENCES}

1. Ambient (Outdoor) Air Quality and Health: Fact Sheets. WHO ; 2018. URL : https://www. who.int/news-room/factsheets/detail/ambient-(outdoor)-air-quality-and-health

2. Health Effects of Particulate Matter. Copenhagen : WHO Regional Office for Europe ; 2013. URL: http://www.euro. who.int/_data/assets/pdf_file/ 0006/189051/Health-effectsof-particulate-matter-finalEng.pdf

3. Health Risks of Particulate Matter from Long-Range Transboundary Air Pollution. Copenhagen : WHO Regional Office for Europe ; 2006. URL: http://www. euro.who.int/_data /assets/pdf file/0006/78657/E 88189.pdf

4. Turos O.I. Medychni perspektyvy. 2008 ; XIII (1) : 93-97 (in Ukrainian).

5. Sevalniev A.I. and Volkova Yu.V. Bulletin of Problems in Biology and Medicine. 2017 ; 4 : 87-91 (in Ukrainian)

6. Air Quality Guidelines - Global Update 2005. Copenhagen : WHO Regional Office for Europe ; 2006. URL: http://www.euro. who.int/_data/assets/pdf file/ 0005/78638/E90038. pdf?üa $=1$

7. Turos O.I., Petrosian A.A. and Mazko L.V. Vykorystannia metodolohii ryzyku pry otsintsi vplyvu dribnodyspersnoho pylu na stan zdorovia naselennia [Use of Risk Methodology at the Assessment of the Impact of Fine Particulate Matter on the Health of the Population]. In : Pershyi Vseukrainskyi zizd ekolohiv: zb. tez dop. [The First All-Ukrainian Congress of the Ecologists. Abstracts]. Vinnytsia : UNIVERSUM ; 2006 : 244-245 (in Ukrainian).

Надійшла до редакції 14.12.2018
2. Встановлено певні закономірності розподілу концент- 